\title{
Rocks, fabrics and magnetic anisotropy: an introduction to the issue in honour of František Hrouda
}

\author{
Manish A. Mamtani • Martin Chadima • \\ Helga de Wall $\cdot$ Reinhard O. Greiling
}

Received: 17 August 2011/Accepted: 28 October 2011/Published online: 27 November 2011

(C) Springer-Verlag 2011

All rocks - igneous, sedimentary as well as metamorphic or tectonically deformed-develop a spatial and geometrical arrangement of their constituent minerals commonly referred to as fabric. The genesis of rock fabric, its orientation and intensity can be directly linked to certain geological processes or, on a larger scale, to tectonic phenomena. For this reason, fabric analysis plays a pivotal role in geological investigation. While in some rocks the fabric can be seen with the naked eye, in the others it can be recognized only with the help of instruments and special techniques. A very effective technique, among others, is the analysis of magnetic fabric based on the measurements of anisotropic magnetic properties. Due to its rapidity, accuracy, low cost and non-destructiveness, magnetic fabric analysis has been successfully applied in all branches of earth sciences for more than five decades.

Because of his pioneering role in the study of magnetic properties of rocks, this issue is dedicated to Professor František Hrouda. It contains 19 papers dealing with magnetic anisotropy measurements in a variety of rocksgranite, gabbro, mica schist, quartzite, obsidian, monzodiorite, syenite, as well as tuffs, clays and Quaternary deposits - and in minerals, such as haematite. The first few papers are of a more fundamental nature, which are

M. A. Mamtani $(\bowtie)$

Indian Institute of Technology Kharagpur, Kharagpur, India

e-mail: mamtani@gg.iitkgp.ernet.in

M. Chadima

AGICO Inc., Brno, Czech Republic

H. de Wall

Universität Erlangen-Nürnberg, Nürnberg, Germany

R. O. Greiling

Karlsruher Institut für Technologie, Karlsruhe, Germany methodology-based and provide the reader with an insight into the variety of problems in rocks and minerals that can be handled using magnetic fabric. These are followed by several papers dealing specifically with the magnetic fabric analysis in igneous rocks. Finally, there are papers addressing problems related to alteration of rocks and highlighting the application of magnetic fabric analysis in understanding various processes in sediments and sedimentary rocks.

The issue starts with a paper by Hirt and Almqvist, on the interference of dia-, para- and ferromagnetic subfabrics in polycrystalline rocks. The paper gives an overview on existing techniques for the isolation of magnetic subfabrics and shows examples for geological application. MartinHernández along with Guerrero Suarez presents two back-to-back papers dealing with magnetic anisotropy of haematite natural crystals. The papers underline the complex behaviour of natural haematite under the influence of different field amplitudes and illustrate the variation in principal directions, shape and degree of anisotropy of magnetic susceptibility (AMS) ellipsoids with changing field magnitude. Cañón-Tapia and Cárdenas report detailed AMS, hysteresis and thermomagnetic experiments on the magnetic properties of obsidian and their implications for measuring AMS. Particularly important is the indication of submicroscopic ferromagnetic mineral constituents, which control the AMS ellipsoid. This result suggests that similar submicroscopic fabrics may be present in further volcanic rocks, but have been overlooked as yet. Kontny et al. present AMS data from measurements taken in low field at room and liquid nitrogen temperatures, as well as in high field, along with Electron Back Scattered Diffraction (EBSD) data on magnetite bearing mylonitic garnet mica schists from the relatively HP-HT metamorphic Seve Nappe Complex (Scandinavian Caledonides). 
They integrate results from these different methodologies to decipher a transition from a simple shear to a pure shear regime during shear zone fabric development. Mamtani and Vishnu demonstrate a positive relationship between the shapes of, respectively, the strain- and AMS ellipsoids in micaceous quartzite. They compare magnetic fabrics, which are dominated by the mica fabric, with shape preferred orientation (SPO) of mica and quartz as well as strain analysis data. The results document the influence of mica grains on the evolution of quartz grain shapes, whose grain boundaries are pinned to the mica grains. Consequently, mica minerals control the shape of the strain ellipsoid and, in turn, the magnetic fabrics.

The past few decades have seen considerable application of magnetic methods, particularly AMS, in the analysis of internal fabric of plutonic rocks. This has helped establish time relationship between emplacement, fabric development and regional tectonics of several plutons in different parts of the world. Because of its high accuracy and relative ease of measurement, it is not an understatement to conclude that today AMS is one of the most efficient methods for analysing fabrics in igneous rocks. We believe that it will continue to play a very important role in the future as well, and there are several papers in this topical issue that assert this. Schulmann and Jezek numerically model evolving fabrics during the ascent of plutons. Modelling results may help in the interpretation of natural magnetic fabrics and allow to distinguish, for example, whether constrictional fabrics originated by extension or by an overprint of different deformation stages. Models also predict the spatial distribution of fabric types in a diapiric intrusion. Similar fabrics are tackled by Žak and Kabele with Finite Element Modelling (FEM). Their numerical simulations on the influence of two different strain regimes on a cooling magma show the development of non-coaxial fabrics in porphyritic plutonic rocks. The modelling documents the contrasting behaviour and strain of different mineral- and grain size-fractions in the solidifying magma and provides new insights for the interpretation of magmatic fabrics and AMS in plutons. Archanjo et al. evaluate emplacement fabrics of a gabbro-norite from SE Brazil by integrating AMS and mineral SPO data and also decipher the shape of the pluton to be sill-like. They also establish that AMS is a reliable indicator of magmatic fabric for a magnetic anisotropy above 1.10. Henry et al. discuss the case of Kapitan-Dimitrievo pluton (Central Bulgaria), where the visible magmatic fabric and magnetic fabric have different orientations. The authors relate this to variation in stress orientation during magmatic evolution of the pluton and infer the pluton to be a late-syntectonic intrusion that marked the last ductile deformation in the Maritsa shear zone. Tripathi et al. integrate magnetic fabric and geochronological information from the Palaeozoic age
Kailash Kinnaur Granite (KKG) and its marginal Cenozoic leucogranites located in the Higher Himalaya. They conclude that the interior of the KKG preserves the original emplacement fabric, while deformation of the external rim of the KKG and crystallization of the leucogranites were synchronous with ductile deformation along the South Tibetan Detachment. Raposo et al. present results from AMS as well as anisotropy of anhysteretic remanent magnetization (AARM) analysis of rocks from the Piracia pluton (Brazil) and use the data to identify location of the magma feeder zone and also areas where fabric developed on account of regional strain. Cifelli et al. demonstrate coaxiality between the magnetic fabric in the magmatic and thermal aureole rocks of the Monte Capanne intrusion (central Italy). They interpret this as an indication of systematic coupling throughout the pluton perimeter and conclude that the metamorphic and magnetic fabrics in the host rocks are synchronous with ascent and emplacement during crustal extension. Kratinová et al. present AMS data from the anatectic crustal domain of the Central Vosges (NE France), where orogenic compression-related fabrics were reworked during subsequent regional extensional deformation. The magnetic fabric is inferred to have developed as a viscous response of stretched partially molten crust during continuous ductile extension. The authors conclude that the finite shape of AMS ellipsoid is highly sensitive to strain regime as well as superposition of orthogonal deformation events.

Weathering and alteration can influence the magnetic fabric and consequently interpretation of the fabric. Hence, a thorough investigation of magneto-mineralogy is important in the analysis of magnetic fabrics. Just and Kontny present mineralogical and thermomagnetic data from the hydrothermally altered Soultz-sous-Forêts granite (upper Rhine Graben, France) and relate the mineralogical variations of Fe-bearing minerals to various stages of magma cooling, uplift and associated fluid activity. Zanella et al. combine AMS and Natural Remanent Magnetization (NRM) data from the tuffs of the Aeolian Islands (southern Tyrrhenian Sea, Italy) to decipher the timing of remanence acquisitions-one while cooling within the explosive cloud and the moving pyroclastic current and the other during cooling after deposition. Maffione et al. use magnetic fabric data from Pleistocene continental clays to decipher the tectonics associated with the low angle Altotiberina Fault (Italy) and discuss possible compressive versus extensional tectonic setting. Magnetic fabric can provide very useful information about regional tectonics, and the paper by Porreca and Mattei demonstrates this aspect by establishing a link between AMS data from the Quaternary deposits in the Picentini Mountains (southern Apennines, Italy) and extensional/transtensional tectonics. Likewise, Márton et al. relate the magnetic fabric of Late Miocene sediments 
from the southern Pannonian basin (Croatia) to compressional/transpressional deformation in the region.

Thus, these 19 papers cover several important aspects associated with magnetic fabric analysis of igneous, sedimentary as well as metamorphic rocks. Data from various countries and various magnetic techniques are presented, and inferences are drawn about strain, regional tectonics, emplacement mechanisms as well as processes that can lead to remanence acquisition. The importance of having a thorough knowledge of magnetic properties and magnetic mineralogy and its implications on proper interpretation of magnetic fabric data is also brought out in this issue. Moreover, the usefulness of integrating magnetic data with SPO data of minerals as well as numerical modelling is highlighted. Thus, it is our firm conviction that this topical issue covers many of the important applications of magnetic anisotropy that will guide future research involving fabric analysis using magnetic methods.
We started planning this issue in the summer of 2009, and we are grateful to Professor Wolf-Christian Dullo, the Editor-in-Chief of the International Journal of Earth Sciences for his relentless support throughout these 2 years. Special thanks to Claudio Rosenberg and Marlina Elburg for editorial handling of a couple of manuscripts and to Don Tarling for willingly agreeing to write a Foreword. Finally, we gratefully acknowledge the several reviewers who gave their valuable time and energy to comment on the manuscripts-Mark Anderson, Carlos Archanjo, Graham Borradaile, Jean-Luc Bouchez, Pierre Camps, Edgardo Cañón-Tapia, Marta Chlupáčová, Carlo Dietl, Eric Ferré, Frank Fueten, Bernard Henry, Fátima MartínHernández, Ann Hirt, Mike Jackson, Jana Just, Agnes Kontny, David Krasa, Zuzana Kratinová, Massimo Mattei, Michael Ort, Massimiliano Porreca, Irene Raposo, Patrice Rey, Marcello Schiattarella, Manuel Sintubin, Ruth Soto, Jean-Louis Vigneresse, Tomasz Werner, Jiři Žák. 